\title{
Research Progress of Domestic Reverse Logistics Management from the Perspective of Circular Economy*
}

\author{
Yabing Li \\ Lanzhou University of Technology \\ Lanzhou, China 730050
}

\author{
Ting Pan \\ Lanzhou University of Technology \\ Lanzhou, China 730050
}

\begin{abstract}
With the development and application of Internet technology, the logistics industry has entered an unprecedented period of development. In order to achieve environmental, economic and social development, circular economy has been identified as an important part of the national development strategy and the reverse logistics is an important way for the development of circular economy. Based on the related literature review of circular economy and reverse logistics from 2003 to 2017 , this paper first summarizes the overall status of domestic research on reverse logistics under the theory of circular economy, and then from the perspectives of the subject and the object, specifically elaborates the research on the implementation of reverse logistics under the circular economy, the author finally combines the actual development of the industry, summarizes the future research directions and priorities of reverse logistics, and hopes to have a certain reference value for research on reverse logistics industry.
\end{abstract}

Keywords-circular economy; reverse logistics; research enlightenment

\section{INTRODUCTION}

With the development of the global economy, resource shortages and environmental pollution have become the constraints for sustainable development in the region. Based on this, circular economy has emerged as a national development strategy. As a fundamental reform of the traditional economic model, the circular economy emphasizes the innovation of "technology" and "policy". The purpose is to satisfy the maximization and optimal allocation of resources for human survival and development. The core of the circular economy is to consider resource conservation under the influence of social and environmental factors and emphasize circulation and recycling of resources. Through literature review, it has been found that domestic studies on circular economy development models focus on three aspects: industrial development, regional development, and social development. Testing units like Jiangsu Province, Shandong Province, Liaoning Province and Guiyang City have achieved certain results in industry, agriculture, service industries and waste recycling. The report of the 19th Congress clearly stated that protecting the ecological

*CLC number: F Document code: A environment is a prerequisite for economic development. Therefore, green development has become the main way to promote social and economic development. In the long term, resources Recycling and the effective protection of the environment still require the common concern of the government, businesses, and society.

With the development and application of Internet technology, the logistics industry has entered an unprecedented period of development. According to the content framework of the circular economy, reverse logistics is one of the important paths for realizing circular economy. Reverse logistics refers to a series activities such as planning, execution, and control of returned goods, various types of packaging, waste articles, contaminated materials, and wastes, as well as associated information flow and capital flow, from the final consumer terminal to the initial supply terminal. The goal is to maximize resource value utilization and minimize environmental impact [1]. The reverse logistics model based on circular economy is to develop positive logistics, that is, "purchase-manufacturing-entity distribution", and at the same time develop reverse logistics formed by the recycling of waste articles and recycling of renewable resources to form a "green collection of raw materials - ecology design - clean production - green consumption - recycling or reproduction" of the recycling logistics system[2]. The domestic research on reverse logistics has yielded a lot of results "Fig. 1". SCI-original periodicals, EI-originated periodicals, and CSSCI periodicals have searched 490 articles on "reverse logistics", while "recycling economy" and "reverse logistics" related documents retrieved 132 articles. We can see from "Fig. 1", since 2000, especially from 2007 to 2008, scholars had focused on circular economy and reverse logistics increasingly. But from 2008 to now, the research craze significantly reduced. This has a certain correlation with the speed of China's economic development. Although China's GDP grew steadily from 2003 to 2017 , the growth rate of the economy has slowed down after 2008 "Fig. 2". This shows that the domestic economy is not only affected by the global financial crisis, but also affected by indirect effects of China's structural adjustment, industrial transfer, etc. Therefore, in order to respond to the development strategy of China's circular economy, a corresponding circular economy system is in urgent need to develop reverse logistics. The 
government should carry out top-level design from the perspective of mechanism construction, etc. Enterprises should construct an operation mode suitable for different industries and products from the perspective of the implementation entity. The healthy development of reverse logistics is guaranteed from the aspects of mechanism, technology and capital; consumers should actively respond to the call of the national government and cooperate with relevant enterprises to participate in reverse logistics activities.
The research of reverse logistics mainly focuses on the following two aspects: subject and object. Subject includes government, enterprises and public consumers, while object refers to waste management and system management innovation. In order to clarity the implement path under the circular economy, the following chapters will focus on literature review from the perspective of the subject and object in "Fig. 1" and "Fig. 2".

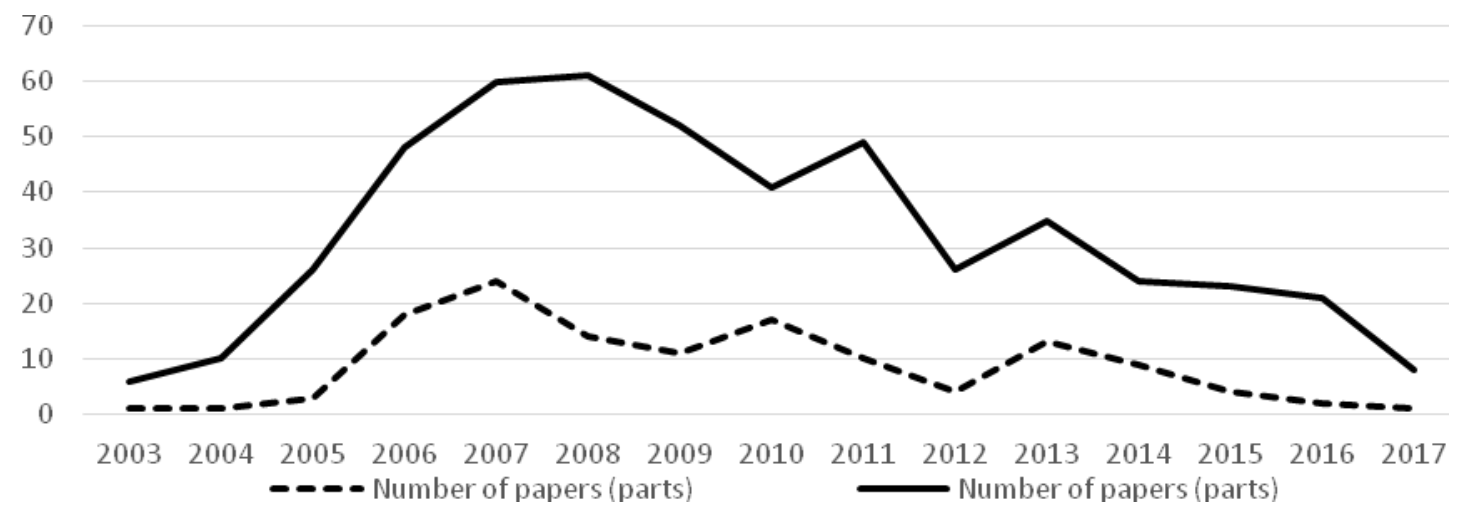

Fig. 1. Distribution map of circular economy and reverse logistics.

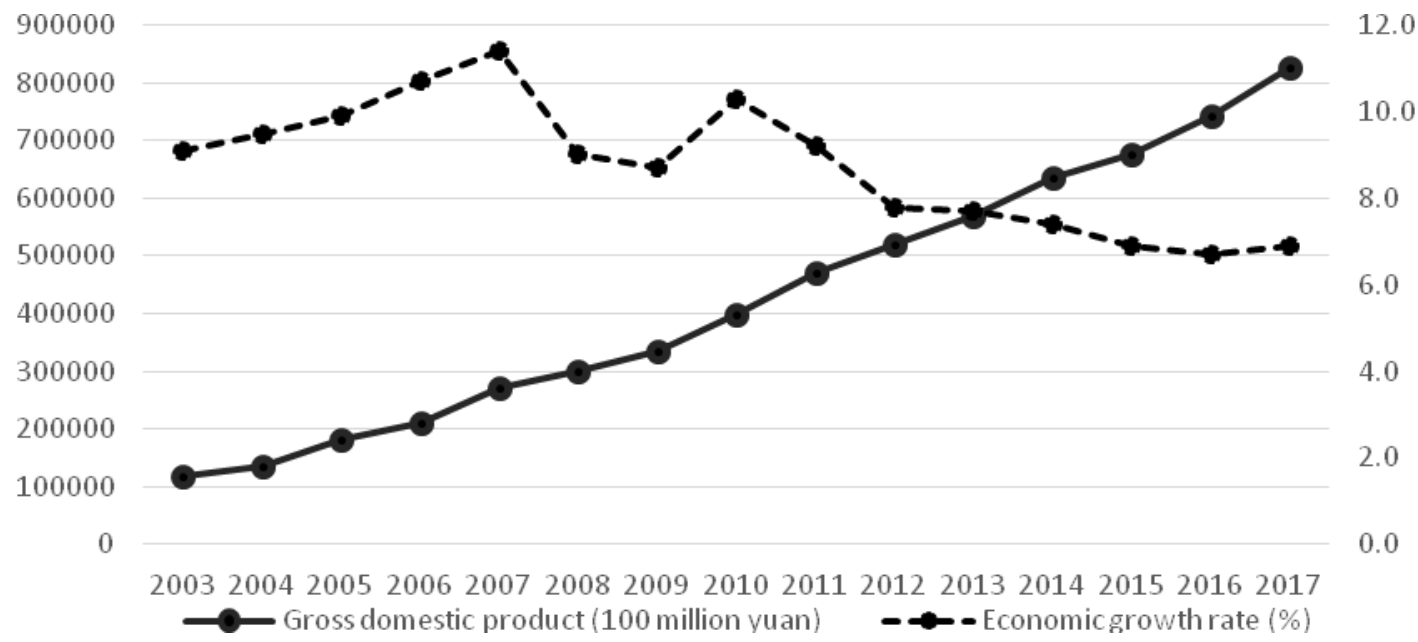

Fig. 2. Gross domestic product and its growth rate, 2003-2017.

\section{RESEARCH ON THE SUBJECT BEHAVIOR OF REVERSE LOGISTICS UNDER CIRCULAR ECONOMY}

The subject of reverse logistics under the circular economy includes government, enterprises and consumers. This is consistent with the "top-down" implementation path of China's circular economy development strategy.

\section{A. Government Level}

In the implementation of circular economy and reverse logistics, the government plays an irreplaceable leading role in the formulation of laws and regulations, industrial policies, and the issuance of financial subsidies and personnel training. From the national and related industry policies and regulations, Wang Liwu et al.[3]pointed out that the legal system of China's reverse logistics will gradually improve by improving the responsibilities of reverse logistics entities, developing third-party reverse logistics industry, formulating laws and regulations for reverse logistics, and improving fiscal and tax incentive mechanisms for the development of reverse logistics. Tang Yan et al.[4] established a threedimensional framework based on policy tools from the latitude of basic policy, scientific and technological research, and renewable resources policy. He put forward as well some suggestions on China's existing related policies on renewable resources: adjust the frequency of application of environmental policy instruments; apply economic policy tools in social and economic development; pay more attention to social policy tools in policies; and give full play to the role of the Internet in the reverse logistics recovery system. In terms of government incentives and subsidies, 
Zhang Baoyin et al. [5]who designed an incentive and supervision model based on the premise of information asymmetry to enable the government to guide enterprises in implementing reverse logistics strategy and related institutional design better, pointed out how the government and the company should enter into optimization contracts, and how the government should increase supervision. Zhou Xianghong et al. [6]designed a government subsidy function related to the recovery rate and remanufacturing rate through optimization of social costs, economic costs, and recycling revenue, and established a dynamic multi-objective and multi-period remanufacturing reverse logistics planning model. Through simulation examples, the sensitivity analysis of the government subsidy parameters is performed, which shows that the positive subsidy can effectively promote the development of reverse logistics. Zheng Weiyan et al. [7] established a reverse logistics network with no government guidance, and a government-directed reverse logistics network joined the government's rewards and penalties mechanism and negative externality constraints of logistics. The implemented only negative externalities of logistics, only implementing reward and punishment mechanisms and simultaneously implementing logistics negative external constraints and reward mechanisms, the three scenarios discuss the impact of government guidance on reverse logistics networks, indicating that the simultaneous implementation can lay out a green and effective reverse logistics network. Zhou Qilei[8]pointed out the basic tactics for the development of reverse logistics in China as a whole, namely, rested with perfecting industry legislation, clarifying the responsibilities of reverse logistics entities, formulating preferential policies to assist the development of reverse logistics companies, and setting up a public platform to improve the overall operational efficiency of reverse logistics; opening up professional trading markets and accelerating the circulation of reverse logistics resources.

\section{B. Corporate Level}

The enterprise is the main body of the market, and it is also one of the indispensable entities in the reverse logistics system. Whether it adopts the manufacturer or retailer recycling model or the third-party logistics company carries out reverse logistics activities, the enterprise is the core of the implementation of reverse logistics. From the perspective of the supply chain, Bao Jianqiang et al [9]proposed the Extended Producer Responsibility (EPR) system, which aims at the entire life cycle of products and points out that manufacturers should bear certain responsibility for the recovery, recycling, and final disposal of products. Gong Ying [10]proposed that a reverse logistics supply chain system should be constructed to implement the reverse logistics recovery item orientation and form a strategic alliance. According to the operation of the Chinese enterprises themselves, the improvement measures of the reverse logistics enterprises are proposed from the four aspects of materials, ideas, networks and new trends. Lin Ping et al.[11]considered an entire supply chain network from the supplier to customers through manufacturers, distribution centers, and established the supply chain network structure optimization model and dual model based on the principle of the overall optimal supply chain operating cost. On the basis of the idea of inverse optimization, it provides a path for the supply chain to establish a dynamic response strategy under the premise of meeting customer requirements through the adjustment and optimization of parameters in the network structure optimization model. Wang $\mathrm{Xu}$ et al. [12]also believe that the development of reverse logistics of enterprises is caused by the internal and external influence factors of reverse logistics. It is necessary to build a reverse supply chain model consisting of processors, recyclers, and consumers. The Stackelberg game is applied to analyze and solve the profit function value of each participant in the reverse supply chain led by the processor, and find the cooperation interval between the processor and the recycler by the La-grange mean value theorem and obtain the benefit distribution plan between the enterprises in the reverse supply chain. The plan provides an in-depth analysis of the company's reverse logistics recovery operation alliance benefit distribution mechanism.

In addition, taking into account the product's full life cycle, Chang Xiangyun et al.[13]introduced the idea of managing reverse logistics and discussed the various stages of the production enterprise's entire life cycle of the product, namely, $R \& D$, production, sales, consumption, and waste processing stage, the main strategies and methods for reverse logistics management should be adopted. Although the management ideas in the waste disposal stage are the focus, reverse logistics management policies and reverse logistics network structures need to be designed, but in order to systematically and comprehensively manage reverse logistics, early preparations and effective cooperation in the previous stages are still needed. Xie Tao [14]also believed that the environmental cost management methods of the company's $\mathrm{R} \& \mathrm{D}$, design, manufacturing, sales, use, and recycling of waste under the clean production model are ecological design, clean production, environmental marketing, and reverse logistics. It is proposed that clean production is a fundamental change to the traditional production model, ie, end-to-end governance. It controls the entire manufacturing process with a new production model, minimizes undesirable inputs from the source, and avoids the generation and emission of pollutants. Under the guidance of Corporate Social Responsibility (CSR), Wen Xiaoqin et al.[15] established a mathematical optimization model through three models of manufacturer recycling, retailer recycling, and third-party logistics recycling. Taking the recycling of used products in the electronics industry as an example, the recovery models with and without considering CSR are compared, and the impact of CSR and government incentives on the selection of waste product recycling models for production companies is analyzed through example analysis. The results show that CSR and appropriate government incentives promote the recovery of waste products by producers themselves. There is positive significance. Peng Yulan et al.[16]implemented the waste "zero emission" target in the eco-industrial park and believed that it was necessary to clarify both the property rights and the responsibilities of the national government, manufacturers, and third-party pollution control companies on waste discharge, and gradually establish the production 
system driven by customer demand, and introduce supply chain and lean management ideas into the system and EDI technology into the supply chain. The construction of ecological industrial clusters can be promoted by the benign interaction of industrial clusters and the third-party pollution control market.

\section{Consumer Level}

At present, some scholars have discussed the behavior of consumers involved in reverse logistics activities, who emphasized that consumers' concerted effort is a must to the implementation of reverse logistics. Li Qian et al [17] pointed out that under the three conditions of government non-regulation, government supervision, and government regulation, corporate and consumer game analysis, only if consumers actively participate in the reverse logistics activities can the company have profitable space and companies will choose to implement the reverse Logistics. Zhang Jingwen et al [18]also indicated that as consumers of products, they should constantly improve their awareness of environmental protection and social responsibility and actively support and participate in reverse logistics activities. Based on the "Internet + " strategy of new media under the network marketing methods, aiming at home appliance consumers (recovery of the beginning of reverse logistics), Liu Yongqing[19]pointed out that a bridge-recycling channels between consumers and businesses should be built, and suitable collection strategies should be put forward for the waste of home appliances recycling processors, namely, convenient and quick linking methods should be designed; mobile, social and other internet media should be used for recycling channel design; more attention should be paid to online community feedback, recycling channels should be standardized; and social network marketing risks should be avoided.

\section{RESEARCH ON REVERSE LOGISTICS OBJECT IMPLEMENTATION ACTIVITIES UNDER CIRCULAR ECONOMY}

The object is the object and means of reverse logistics activities, including three aspects of industry and regional waste management and system management innovation.

\section{A. Industrial Waste Management Study}

The implementation of reverse logistics activities under the circular economy has strong industry attributes. Agriculture is the foundation of national economic construction. Domestic scholars have done a lot of research on agricultural reverse logistics. In the selection of recycling modes, $\mathrm{Xu}$ Jianguo[20], Li Tao[21]proposed the development mode of rural reverse logistics to be implemented from the perspectives of operational subjects, channel models, classification of recycled goods, etc. However, due to different operators, channel modes are different, so the former proposed two reverse logistics channel modes: to establish a collection point for used products in each village; to establish a recycling center and processing center for waste articles in the area, or set up a recycling center directly in the area, instead of setting up a collection point in each village. The latter believed that there are three types of reverse logistics channels: sharing of positive logistics channels, self-built recycling centers, and establishment of a joint recycling center. Qiu Yan[22]discussed the operation mode of agricultural product reverse logistics in the main flow stage of agricultural product logistics and circular economy mode, and put forward relevant implementation countermeasures, namely increasing the flow of positive logistics of agricultural products; actively promoting the related technologies of reverse logistics of agricultural products Development; perfecting policies and measures, improving laws and regulations; vigorously developing third-party reverse logistics and carrying out pilot demonstrations. Pang Yan et al. [23]also proposed the mode of straw waste logistics such as straw fertilizers, energyization of straw, feedstuffs of straw, cultivation of straw-based edible fungi, raw material of straw, and returning land to the field of straw based on the current situation of recycling and utilization of crop straw resources in Hunan Province, China. He pointed out specific implementation measures for the logistics mode of crop straw waste as well from the three aspects of strengthening publicity, doing a good job of policy guidance and economic support, and improving infrastructure. In the network structure design, Wang Xinli[24]pointed out that due to the existence of reverse logistics networks for recoverable value items and waste disposal, a complete reverse logistics model network structure for rural waste products should include a first-level recycling station, secondary recycling stations and tertiary recycling stations. It showed through examples that the establishment of secondary recovery points can save costs.

There are scholars studying the pharmaceutical industry and coal companies, analyzing the status quo of reverse logistics development and put forward corresponding countermeasures. Zheng Luoping et al.[25]proposed development strategies in view of relevant subjects concerning drug reverse logistics: importance should be attached to cultivating the concept of reverse logistics management in the drug logistics industry; drug research and production process management, the management of the drug reverse logistics process should be further strengthened; and the efficiency of the reverse logistics of drugs should improve. In order to improve the operational efficiency of reverse drug supply chain and post-recovery processing stages, HouYanhong et al.[26]put forward the optimization of supply chain structure in drug recovery, reverse logistics based on the idea of cooperation, rationalization of supply chain financing and distribution of benefits, government policy guidance and supply chain cooperation contract standardization, and in-depth cooperation in logistics and information technology from the four dimensions of structure, capital, system, and technology. Aiming at shaping the "green" culture of coal enterprises and extending the industry chains and optimization of industrial structure adjustment, GuYanyan et al. [27] proposed a corresponding strategy for coal companies to implement reverse logistics, based on the two stages of coal enterprise recovery of coal production and waste disposal associated with coal production, emphasizing that coal companies' constructing and implementing reverse logistics would help adjust their 
industrial structure, so as to become familiar with and master the closed-loop process of coal mine resources. He Chao et al. ${ }^{[28}$ proposed a four-module coal mine reverse logistics management information system, including basic information management, information tracking management, return flow management and reuse management based on Internet of Things technology application, and pointed out that in order to realize the management information system, the effective implementation within an enterprise requires not only the development of the system itself, but also the related management organizations, processes, and management systems. It is therefore necessary to establish an unified information management department composed of managers of various information resources of the company.

\section{B. Research on Waste Management at the Regional Level}

The study of reverse logistics at the regional level is mainly based on the development status of various regions in China and some countermeasures are put forward to facilitate the effective recovery and management of waste. On the provincial level, Wang Tingrui[29]pointed out that the environmental problems in Liaoning Province have had already been outstanding. On the one hand, the green supply chain logistics system should be constructed at the regional level, on the other hand, it is necessary to create green corporate logistics system. In the county area, in order to realize the value-added of waste, Liao Zao et al.[30]built a county-level recycling logistics system, which included multiple cycles at the enterprise level, the middle cycle at the park level, and the large-scale cycle at the regional level. Some concrete measures have been proposed from the point of view of material recovery, namely, the recovery of waste articles, the classification of waste products recovered, the repair or recovery of recycled waste products, and the sale of recycled products.

Also, in the urban context, Zhu Haibo[31] and Liu Ping et al.[32]emphasized that joint efforts of the government and enterprises should be made to ensure the effective operation of the city's reverse logistics system. Zhu Haibo[31]found the problems that restricted the development of China's urban reverse logistics from the successful experience of developing urban reverse logistics in foreign countries. It is recommended to study the "comprehensive waste management" law that mobilized all the people to participate in 3R (reducing waste, making best use of it, recycling) action. Taking Harbin as an example, it is necessary to plan a logistics system, that is, an urban recyclable logistics system, which could effectively support the recycling of urban resources, to solve the major problems of high circulation costs and difficulty in improving economic benefits. According to the current situation of urban reverse logistics implementation in the central region. Liu Ping et al.[32]found that the reverse logistics was a low-end, extensive and unsustainable development mode. Taking Nanchang City as an example, the game theory was used to analyze the status quo of reverse logistics implementation between the government and enterprises, between the government and the citizens, to help the government regulate the behavior of enterprises and regulate the recycling behavior of consumers. Tang Jianrong et al.[33]used the Jayaraman site selection model to conduct a practical study on the location of the electronic product recycling stations and site selection problem of rework station by taking the urban area of Wuxi as an example. They linked the actual problems encountered in the site selection process with the trend of government policy, and provided reliable scientific basis and strong policy recommendations for Wuxi's overall reverse logistics site selection from four aspects: building a scientific indicator system, encouraging relevant technological innovation, strengthening government guidance, and regulating legal supervision strictly. On account of the recycling status of renewable resources in Beijing, Liu Tingting et al. ${ }^{[34]}$ also put forward a proposal of establishing a reverse logistics recycling system, innovative "Internet +" renewable resource recycling model, constructing upstream and downstream links, raising industry barriers, increasing fiscal and taxation policy support to encourage formal recycling enterprises, planning and sharing statistical information platforms to promote Beijing's recycling system of renewable resources.

\section{Research on Logistics Management System Innovation}

The development of reverse logistics is inseparable from the system technological innovation. With regard to the establishment of the enterprise's reverse logistics system and system, Zhang Zhijun et al.[35]applied the advanced statistical monitoring, data analysis, and information release methods and technologies at home and abroad to build a "triple quadruple" green logistics statistical monitoring model and monitoring system for the first time. And they had established a monitoring object system that integrated the "three-fold" (regional, industry, and corporate) green logistics statistics monitoring subject and the "four points" ("point-line-surface-body"). Ni Ming[36,37] specifically pointed out that the company's reverse logistics system had two variables of operating time OT and operating cost OC, Game Theory is used to analyze the effective ways of realizing the economic benefits of waste logistics in supply and demand node enterprises. He pointed out that the improvement of the informatization level of the reverse logistics system was conducive to the realization of the Pareto optimal state of the contradictory variables of OT and $\mathrm{OC}$, and gave five modes of reverse logistics based on design, manufacture, distribution and consumption and their conversion relationship. Zhang Qun et al.[38]established a multi-objective stochastic programming model based on the demand of market demand, scrap recycling, and the uncertainty of the quality of recycled products in order to minimize the cost of logistics networks and minimize the impact on the environment to determine the locations and numbers of factories and recycling processing centers in the reverse logistics network and distribution of material flows between network nodes, and the constraint method is used to transform multi-objective model into a single-objective model, and CPLEX 12.6 was called on the MATLAB 2014a platform. The validity of the model is verified by examples.

In addition, some scholars also gave their own opinions upon recycling based on the characteristics of certain wastes, 
which provided a valuable reference for the enterprise's reverse logistics management. On the recycling of used cars, Gan Junwei et al.[39] applied decision-making and evaluation laboratory (DEMATEL) methods from the three dimensions of government, enterprises and automotive users to identify end-of-life vehicle recycling models and reverse logistics networks, national industrial policies, laws and regulations, personnel quality, environmental awareness and other factors are the key factors affecting the recycling of end-of-life vehicles, indicating that the government played a key role in the development of the industry, and enterprises played a central role in the development of the recycling and recycling industry of end-of-life vehicles. In order to promote the effective recovery and use of end-of-life vehicles, Dai Ying, etc.[40]constructed a structural model of the automobile reverse logistics system, which was mainly composed of the four system elements: participants, logistics elements, reverse logistics channels, and systems. Based on the greenness evaluation criteria, the evaluation index system of the automobile reverse logistics system was constructed, and a comprehensive evaluation method combining fuzzy comprehensive evaluation method and data envelopment analysis (DEA) was proposed. Zhou Zhifang, etc.[41]considered the internal consumption, external damage and value factors in the enterprise reverse logistics management in the cost decision-making. The reverse logistics cost accounting and optimization model has been redesigned and perfected. The example of a waste automobile recycling company in Hunan Province was taken to analyze the operation and management costs. The proportion of dismantling points was the highest. Therefore, improving the efficiency of operation and management of dismantling points was the most effective breakthrough to reduce the cost of the entire system. This provides a reference for the effective operation of automobile reverse logistics. He Zhenggang et al.[42] analyzed five types of endof-life vehicle recycling models based on different recovery subjects from the aspects of operational processes, mode strengths and weaknesses, scope of application, and domestic and international applications. The comparison between models was made from the six dimensions of recovery costs, economies of scale, information feedback, recycling efficiency, the degree of professionalism and risk assumptions. Based on the actual situation of China's end-oflife vehicle recycling, it was recommended that the recovery model be based on the combination of third-party recycling companies and other recycling entities. Liang Ling et al. ${ }^{[43]}$ also tried to improve the recycling efficiency and incentives for the recycling of old car parts. They used the foreign recycling channel policy to compare and analyze the autonomous recycling models, outsourced recycling models, and joint recycling models of old automotive parts. Consumers can actively recycle old car parts and purchase auto remanufactured parts; taxi or rental companies could be cooperated to recycle old car parts; forward sales network could be relied on to establish sub-regional recycling networks; and automobile manufactures should be worked with to recall the scrap parts of automobiles during the warranty period and product life cycle.
On the recovery of waste electrical and electronic products, on the basis of the Internet+ recycling model and specific operational processes led by different stakeholders, such as Internet companies, recycling companies, and manufacturing companies, Wei Jie[44]put forward a proposal to increase social publicity, improve the public's awareness of Internet recycling and participation; strengthen platform construction, improve Internet recycling resource database; increase government support for Internet recycling; integrate recycling industry, improve Internet recycling cooperation and other recycling strategies. Lv Jun et al.[45]introduced the spatial statistics kriging method and proposed a spatial mathematical model for predicting reverse logistics recovery of waste electrical and electronic products (WEEE). Based on the principle of unbiased prediction and minimum variance, the Monte Carlo Simulation Example and the results of the case study with Shanghai J Company showed that the model can well analyze the spatial correlation structure of each recovery network, and accurately predicted the WEEE recovery of the unknown network and the entire area through the known network data. Liu Zhifeng et al.[46]analyzed the relationship between the second-hand market demand for waste electrical appliances and the finished product rate obtained after remanufacturing/recycling, and established a reverse logistics inventory model based on a pull strategy. It pointed out that the reusable ratio had a significant impact on the average total cost compared with the remanufacturing ratio, which was a key parameter affecting the average inventory cost. When the remanufacturing rate has already met the recovery rate, the effect of the increase in remanufacturing rate (capacity) on the average total cost became smaller. Zhang Yingxin[47]also studied on the reverse logistics of a certain type of special high-tech products and the inventory forecasting demand of the closed-loop supply chain. It mainly analyzed the prediction methods of BP neural network mainly for inventory demand, and compared this method with traditional statistical analysis methods. It pointed out that BP neural network had great advantages in prediction accuracy, sample selection and systematic error.

\section{CONCLUSION}

This paper regards the implementation path of reverse logistics under the circular economy as the " $3+3$ " mode: 3 subjects and 3 objects. It emphasizes that only by strengthening government legislative system innovation and policy support, improving corporate management and social responsibility, and increasing awareness and enthusiasm of consumer ecological civilization construction can all parties implement objects of reverse logistics activities in a smooth manner. However, through the above review of domestic literature, it can be seen that the research of reverse logistics in circular economy is concentrated on the status quo and countermeasures, system construction, cost optimization, network structure optimization and strategic management, There are few studies on aspects such as the organization model and interest distribution mechanism of reverse logistics entities, channel integration, information technology optimization management, and general development strategy for reverse logistics companies. In order to meet the needs of 
domestic circular economy objectives, in the practice of reverse logistics enterprises, it is urgent to clarify the distribution mechanism between relevant stakeholders and to integrate existing channels with advanced technologies, so as to find out the universal development strategy with greater resource utilization. Therefore, future research focus can be considered from the following aspects.

\section{A. Research on Reverse Logistics Organization Mode}

The related research of reverse logistics under the domestic circular economy is a "top-down" organizational mode. In the future, the "bottom-up" organizational mode can also be explored. Because only in-depth understanding of the status quo of reverse logistics activities at the beginning of recovery, can appropriate countermeasures be formulated to prevent the emergence of bullwhip effect. Changing "push strategy" to "pull strategy" will certainly promote the healthy development of reverse logistics to some extent.

\section{B. Research on Reverse Logistics Management System and Internal Mechanism}

First, we can start with the study of the interaction mechanism with traditional logistics, and explore how to make full use of the existing traditional logistics channels to achieve the smooth implementation of reverse logistics; Secondly, with regard to the interest distribution mechanism of reverse logistics participants, some relevant laws and regulations, industrial policies and financial subsidies should be introduced in succession, which were put into trial use at various demonstration sites, and then promoted step by step, the training of reverse logistics professionals should be strengthened to make it better for the reverse logistics business services; Finally, in the field of technological innovation research in reverse logistics, it is necessary to imitate the classification of accounting software and develop some application software, which is divided into generalpurpose and special-purpose. With trial use, they can be applied specifically by companies to reverse logistics implementation activities after simulated prediction.

\section{Case Studies of Reverse Logistics Companies}

To found a universal strategy for reverse logistics development, some relevant scholars need to have a deeper understanding of the companies that implement reverse logistics and carry out case studies. In addition, it is imperative to carry out empirical research on reverse logistics in multiple industries and areas.

\section{REFERENCES}

[1] Wang Yongkang. Research on the Reverse Logistics Model Based on the Concept of Circular Economy [J]. Business Times, 2010, $27: 27+131$

[2] Lei Xunping, Bao Jufang. Research on Reverse Logistics Management Mode Based on Circular Economy [J]. Commercial Age, 2007, 30:20+22

[3] Wang Liwu, Yang Liu. The improvement of China's reverse logistics legal system [J]. Management Modernization, 2011, 01:14-16.
[4] Tang Yan, Li Kaihang, Li Jian, et al. Applied Research on Policy Framework of Reverse Logistics Industry Policy Based on Policy Tools[J]. Journal of Information, 2016,3505:15-19+71.

[5] Zhang Baoyin, Wang Bo, Wu Yu. Government incentive and supervision based on circular economy model $[\mathrm{J}]$. Chinese Management Science, 2006, 01: 136-141.

[6] Zhou Xianghong, Gao Yang, Ren Jian, et al. Multi-objective location selection model and algorithm for remanufactured reverse logistics under government subsidies [J]. Systems Engineering-Theory \& Practice, 2015, 3508:1996-2003.

[7] Liang Wen, Chen Guangqiang, Wang Xin. Reverse Logistics in the Development of E-Commerce: A Game Analysis of Different Interest Relationships between E-commerce Firms, Government, and Consumers [J]. Sankei Review, 2017, 8(01): 67-79.

[8] Zhou Qilei. Research on the government strategy for the development of China's reverse logistics [J]. Economic Review, 2007, 01:32-33.

[9] Bao Jianqiang, Yu Fan, Chen Yaqing. Research on Producer Extended Liability System [J]. Chinese Industrial Economy, 2007, 08:98-105

[10] Gong Ying. Accelerating Reverse Logistics Construction in Circular Economy [J]. China's Circulation Economy, 2006, 06:15-18.

[11] Lin Ping, Zhang Xiangbin. Optimal configuration of supply chain network structure based on inverse optimization method [J]. Statistics and Decision, 2015, 04:50-53.

[12] Wang Xu, Dai Ying, Lin Yun, et al. Research on Benefit Distribution Mechanism of Reverse Supply Chain Based on Circular Economy[J]. Journal of Chongqing University(Social Sciences Edition),2009,06:52-56.

[13] Chang Xiangyun, Huo Jiazhen, Chen Shiang. Reverse Logistics Management for Product Life Cycle [J]. Statistics and Decision, 2006 13: $166-167$.

[14] Xie Kun. Research on Environmental Cost Management Based on Cleaner Production [J]. Ecological Economy, 2010, 12: 125-128.

[15] Wen Xiaoqin, Dong Yanru. The selection of reverse logistics recovery mode based on corporate social responsibility $[\mathrm{J}]$. Operations Research and Management, 2016, 2501: 275-281.

[16] Peng Yulan, Li Junhua. Industrial Agglomeration, Third Party Waste Management, and Eco-Industrial Park [J]. Theory and Practice of Finance and Economics, 2008, 06:96-100.

[17] Li Qian, Zhou Guohua, Cai Yuanyuan. Game Analysis of Various Interested Parties in Reverse Logistics of Enterprises [J]. Business Times, 2008, 25:47.

[18] Zhang Jingwen, Chen Jian. Research on Green Reverse Logistics Based on Sustainable Development[J]. Science and Technology Management Research, 2008,04:139-141.

[19] Liu Yongqing. The revolution of the home appliance reverse logistics marketing model under the "Internet + " strategy $[\mathrm{J}]$. China's circulation economy, 2015,2906: 30-35.

[20] Xu Jianguo. A Preliminary Study on the Development Model of Reverse Logistics in Rural Areas [J]. Commercial Age, 2010, $09: 31+138$

[21] Li Tao, Yao Yang. The main body, channel and pattern of rural reverse logistics development [J]. Business Times, 2013, 18:37-38.

[22] Qiu Yan. Research on Reverse Logistics of Agricultural Products under Circular Economy Model [J]. Resource Development and Market, 2009,09:823-826.

[23] Pang Yan, Yan Xiaolan. The construction and implementation of agricultural waste logistics model under circular economy-A case study of recycling and utilization of crop straw resources[J]. System Engineering, 2010, 11:82-85.

[24] Wang Xinli. On Rural Reverse Logistics and Its Network Model Design [J]. China's Circulation Economy, 2007, 02:19-21.

[25] Zheng Luoping, Sun Wenbo. Innovation orientation of China's pharmaceutical reverse logistics management based on green orientation[J]. Business Era, 2010, 16:37-38. 
[26] Hou Yanhong, Zhang Fan. Current status and countermeasures of China's reverse drug supply chain operation [J]. Management Modernization, 2016, 3601:115-117.

[27] Gu Yanyan, Li Xinchun. Research on the strategic value and management strategy of coal enterprises to implement reverse logistics [J]. Coal Technology, 2010, 01:10-12.

[28] He Chao, Zhuang Yuliang, Wang Jianjun. Study on Coal Mine Reverse Logistics Management Information System Based on Internet of Things [J]. Science and Technology Management Research, 2013, 3310: 171-174.

[29] Wang Tingrui. Study on the Construction of Liaoning's Green Logistics System Based on Circular Economy [J]. Reform and Strategy, 2010, 04:120-122.

[30] Liao Zao, Luan Guiqin. Constructing county-level three-tiered circulation logistics system: An analysis based on the perspective of reverse logistics [J]. Finance and Economics, 2007, 12: 83-85.

[31] Zhu Haibo. Status and Suggestions of Reverse Logistics Development in Harbin City [J]. Business Studies, 2008, 06:188-190.

[32] Liu Ping, Xiao Jianwei. Status Quo and Countermeasures of Reverse Logistics for Urban Development in Central Region: A Case Study of Nanchang City [J]. Business Economy, 2012, 07: 134-136.

[33] Tang Jianrong, Zhang Xueping, Chen Zhenhuan. Research on the Location Selection of Reverse Logistics Network for Electronic Products for Circular Economy[J]. Resource Development \& Market, 2013, 09:916-919.

[34] Liu Tingting, Wu Yufeng, Gong Yu, et al. Suggestions for Promoting Beijing's Perfect Recycling Resource Recovery System [J]. Environmental Protection, 2016, 4413:31-33.

[35] Zhang Zhijun, Sun Xiaofei. Construction of Statistical Monitoring and Monitoring System for Green Logistics[J]. Statistics and Decision, 2013, 04:25-27.

[36] Ni Ming. Improve the Enterprise Reverse Logistics System with the Concept of Supply and Demand Network [J]. Statistics and Decision, 2008, 11: 170-171.

[37] Ni Ming. The Concept and Mechanism of the Construction of Enterprise Reverse Logistics System [J]. Statistics and Decision, 2009, 01: 166-168.

[38] Zhang Qun, Wei Lirong. Multi-objective stochastic programming model for reverse logistics network design [J]. Soft Science, 2015, 2910: $120-124$

[39] Gan Junwei, He Zhenggang, Peng Mao, Liao Wei. Analysis of Influencing Factors of China's End-of-Life Automobile Recycling Industry Development Based on DEMATEL Method[J]. Science and Technology Management Research, 2016, 3601:103-107.

[40] Dai Ying, Jiang Changbing. Research on Green Degree Evaluation of Automotive Reverse Logistics System[J]. Computer Engineering and Applications, 2009,35:220-222+229.

[41] Zhou Zhifang, Cai Yanfei. Research on Optimization of Reverse Logistics Cost for Automobile Recycling Enterprises Based on Value Stream Analysis[J]. Soft Science, 2016, 01:124-128.

[42] He Zhenggang, Gan Junwei, Liao Wei. Analysis and selection of scrap vehicle recovery models based on different recycling subjects[J]. Ecological Economy, 2013, 01:106-108+130.

[43] Liang Ling, Chi Linna, Xie Jiaping. Recycling channel strategy for automobile reverse logistics $[\mathrm{J}]$. Contemporary Economic Management, 2015, 3701:33-39.

[44] Wei Jie. Construction of "Internet +" Recycling Mode for Waste Electrical and Electronic Products[J]. Science and Technology Management Research, 2016, 3621: 230-234.

[45] Lv Jun, Xie Jiaping. Research on the Prediction of WEEE Reverse Logistics Based on Spatial Correlation[J]. Journal of Industrial Engineering and Engineering Management, 2015, 2904:152-161.

[46] Liu Zhifeng, Zhao Peng, Huang Haihong, Xu Zeying. Reverse logistics inventory model for remanufacturing/reusing of waste electrical appliances[J]. Chinese Journal of Environmental Engineering, 2017, 11(08):4708-4717.

[47] Zhang Yingxin. Prediction of Reverse Logistics Parts Inventory Based on BP Model [J]. Statistics and Decision, 2013, 23:43-45. 